\title{
Three-dimensional simulation of transport processes within blended electrodes on the particle scale
}

\author{
Michael Kespe | Susanne Cernak | Marco Gleiß | Simon Hammerich | Hermann Nirschl
}

Institute of Mechanical Process Engineering and Mechanics, Karlsruhe Institute of Technology (KIT), Karlsruhe, Germany

\section{Correspondence}

Michael Kespe, Institute of Mechanical Process Engineering and Mechanics, Karlsruhe Institute of Technology (KIT), Straße am Forum 8, Karlsruhe 76131, Germany.

Email: michael.kespe@kit.edu

\section{INTRODUCTION}

Increasing the performance of lithium-ion batteries is crucial for its application in the field of electromobility. In this context, the main focus is on amplifying the

\begin{abstract}
Summary
An electrochemical model that is capable to simulate charge and species transport within the three-dimensional particulate cathode structure of lithium-ion battery half-cells is applied to blended electrodes. The electrodes are assumed to consist of physical mixtures of $\mathrm{LiMn}_{2} \mathrm{O}_{4}$ (LMO) and $\mathrm{Li}\left[\mathrm{Ni}_{1 / 3} \mathrm{Co}_{1 / 3} \mathrm{Mn}_{1 / 3}\right] \mathrm{O}_{2}$ (NMC) as cathode active materials. The results of the numerical simulations reveal that there is a significant temporal variation in the distribution of the intercalation current between the active materials on the particulate level. In this context, the LMO component was found to be electrochemically inactive at the beginning and at the end of a simulated discharge process that leads to the identification of a suitable operating window of the half-cells between $0.2<D O D<0.8$. It is shown that within this range, a relaxation of the maximum lithium concentration gradients within the NMC component is achievable. As this provides indications of reduced mechanical stresses within the active material particles, an increased cycling stability of this kind of blended electrodes is expectable. Because of the NMC component's higher volumetric capacity compared with LMO, the separator-near arrangement of NMC allows the magnitude of ionic current density to be reduced by up to $11 \%$ compared with a random particle arrangement. As this indicates a reduction of potential temperature-induced side reactions of the electrolyte, an increased cycle life of the half-cells, especially for high-performance applications, is anticipated. Consequently, multiple-layer coating processes appear particularly attractive for the production of optimized blended positive electrodes for lithium-ion batteries.
\end{abstract}

\section{KEYWORDS}

blended electrodes, cell performance, electrode microstructure, lithium ion battery, numerical simulation

energy and power density, the cycle life, and the safety of the batteries. A novel approach to achieve this target is to manufacture electrodes consisting of different kinds of active materials. Consequently, the active components can be combined according to their individual performance in such a way that the produced electrode is suited 
better to the designated field of application, compared with what is possible with any individual component. Therefore, a so-called blended electrode consists of a physical mixture of at least two different intercalation materials. $^{1,2}$

In order to generate synergies regarding power and energy density, blended electrodes consisting of LMO and NMC are frequently used. For example, LG Chem Ltd. developed such a lithium-ion battery for the hybrid vehicle Chevrolet Volt that was produced by General Motors in 2010/11. ${ }^{1,3}$

$\mathrm{LiMn}_{2} \mathrm{O}_{4}$ shows good performance characteristics at high discharge rates while providing high material availability and low procurement costs. ${ }^{4}$ The disadvantage of LMO is the relatively low usable capacity during discharge, the low cyclic aging resistance and its low electrochemical performance at elevated temperatures. ${ }^{3,4}$ Compared with LMO, the NMC active material has a $22.5 \%$ higher gravimetric energy density and a mean equilibrium potential that is about $5 \%$ lower. $^{1}$

There have been plenty of experimental investigations on blended electrodes in the past. ${ }^{3-8}$ But as this approach targeting the optimization of blended electrodes in general proves to be time-consuming and expensive due to the complexity of the system, the cost of materials, and the required measuring equipment. Numerical simulations are a valuable addition as the effective combination of both approaches has the potential to increase the efficiency and effectiveness of the research on blended electrodes.

Albertus et $\mathrm{al}^{9}$ extended the porous electrode model based on the theory of concentrated solutions developed by Doyle et $\mathrm{al}^{10}$ for the consideration of several active materials. In numerical and experimental studies, they considered the electrochemical behavior of coin cells, with positive electrodes consisting of different fractions of NCA and LMO. An all LMO electrode outperformed a pure NCA electrode at high discharge rates. However, NCA showed a higher specific energy density compared to LMO at low discharge rates. The simulated electrochemical characteristics were in quantitative agreement with experimental data over a wide range of galvanostatic discharge rates.

Appiah et $\mathrm{al}^{3}$ experimentally and numerically investigated the electrochemical behavior of blended electrodes consisting of $\mathrm{LMO}$ and $\mathrm{Li}\left[\mathrm{Ni}_{0.6} \mathrm{Co}_{0.2} \mathrm{Mn}_{0.2}\right] \mathrm{O}_{2}$. The numerical studies were also carried out using the pseudo-2D model, ${ }^{10}$ which was extended to model several active components. In their study, the combination of two models describing the degradation because of the solubility of $\mathrm{Mn}^{2+11}$ and the growth of the so-called solid-electrolyte interphase (SEI) ${ }^{12}$ represented the aging behavior of the cells with good accuracy.
Furthermore, Mao et $\mathrm{al}^{13}$ used the extended porous electrode model of Doyle et $\mathrm{al}^{10}$ to numerically investigate blended electrodes consisting of LMO and NMC. In their study, the contribution of varying particle sizes of the active materials on the utilizable capacity of simulated half-cells at different discharge rates was analyzed.

Similar to Lu et al, ${ }^{14} \mathrm{Jung}^{15}$ and Mao et $\mathrm{al}^{16}$ developed a model predicting the equilibrium potential of electrodes composed of different active materials. By comparison, with experimental studies on the cyclic degradation behavior of mixed material electrodes, Lu et al ${ }^{14}$ showed that this model allows to make statements about the degree of degradation of the individual active components. Mao et $\mathrm{al}^{16}$ used the model to determine the composition of initially unknown blended electrodes.

The herein presented literature overview on the simulation of blended cathodes of lithium-ion batteries is limited to a model extension of the porous electrode model of Newman and Tiedemann ${ }^{17}$ or Doyle et al. ${ }^{10}$ All these models have in common that the particulate structure of the electrodes is modeled by macroscopic parameters, ie, the tortuosity and porosity. Consequently, local effects within the particulate electrode structure are not accessible.

To overcome this drawback, three-dimensional electrochemical models, covering the charge and species transport within fully resolved lithium-ion batteries, have been developed in the past. ${ }^{18-20}$ In previous studies, such a model was implemented within the open source simulation platform OpenFOAM of version 2.2.2 and applied to the investigation of the influence of different 3D electrode structures on the half-cell performance. ${ }^{21}$ In another study, this model was used to spatially optimize the conductivity distribution of a given particulate electrode structure. ${ }^{22}$ In this contribution, the mentioned model is further extended to cover blended electrodes, which, according to the literature, represents a novelty in lithium-ion battery research.

After a brief presentation of the underlying model equations and the parameters used for the simulations, the model is applied to blended electrode structures consisting of different fractions of LMO and NMC. Prior to the evaluation of the numerical results on the particle scale, the numerical experiments are looked at from the macroscopic viewpoint. This is possible as the simulated lithium-ion half-cells are periodically extendable in the electrode plane, which makes the numerically obtained discharge curves that are representative for macroscopic half-cells. Finally, the influence of a stratified arrangement of the active materials within the electrode structure on the expected half-cell performance of the lithium-ion battery is investigated. 


\section{ELECTROCHEMICAL MODEL ON THE MICROSCALE}

The electrochemical model considers the charge and species transport within a spatially resolved particulate cathode of a lithium-ion battery half-cell. The anode is assumed to consist of metallic lithium, which is represented by a suitable boundary condition. The computational domain of the half-cell consists of two nonoverlapping subdomains: the particle resolved solid cathode $\Omega_{\mathrm{S}}$ and the liquid electrolyte $\Omega_{\mathrm{E}}$, respectively. In the scope of this contribution, the cathode is assumed to be made up of a mixture of two different active materials $m$, namely, LMO and NMC. In order to render the numerical results representative for macroscopic half-cells, periodically extendable electrode microstructures are considered. In Figure 1, the underlying model equations and boundary conditions of the microscale model are illustrated.

The conduction of electrons within the subdomain of the positive electrode $\Omega_{\mathrm{S}}$ is modeled by the conservation of charge equation

$$
\nabla \cdot\left(\kappa_{S, m} \cdot \nabla \Phi_{S}\right)
$$

In Equation (1), $\kappa_{S, m}$ and $\Phi_{S}$ denote the electrical conductivity of the active material $m$ and the electrical potential, respectively.

Within the active material particles, the transport of lithium is modeled by solid-state diffusion

$$
\frac{\partial c_{S}}{\partial t}=\nabla \cdot\left(D_{S, m}(\vec{x}) \cdot \nabla c_{S}\right)
$$

Here, $c_{S}$ and $D_{S, m}$ represent the lithium concentration field and the solid state diffusion coefficient of the active material component $m$ within the solid electrode subdomain $\Omega_{\mathrm{S}}$, respectively. In order to account for different active material properties, the spatial distribution of the diffusion coefficient $D_{S, m}$ is adjusted to the position of the active material particles. Within this contribution, only isotropic transport properties are considered. As explained elsewhere, ${ }^{22}$ the interparticle contact points are modeled as electrochemically inert material. In order to suppress lithium transport within these regions, the diffusion coefficient is set to an arbitrary but very small value.

The electrolyte phase is modeled by means of the concentrated solution theory. ${ }^{23}$ Therefore, within the electrolyte's subdomain $\Omega_{\mathrm{E}}$, the coupling between charge and species transport is considered, and charge neutrality is presumed. ${ }^{24}$

$$
\begin{gathered}
\frac{\partial c_{E}}{\partial t}=\nabla \cdot\left(D_{E} \cdot \nabla c_{E}+\frac{\overrightarrow{i_{E}} t_{+}^{0}}{F}\right), \\
{\overrightarrow{i_{E}}}=-\kappa_{E} \nabla \Phi_{E}+\frac{2 R T \kappa_{E}}{F}\left(1-t_{+}^{0}\right) \nabla \ln \left(c_{E}\right) .
\end{gathered}
$$

Here, $c_{E}, \Phi_{E}$, and $\overrightarrow{i_{E}}$ is the concentration field of the lithium ions, the field of the electrical potential and the ionic current density field within the electrolyte phase, respectively. In addition to that, $\kappa_{E}, t_{+}^{0}$, and $D_{E}$ denote
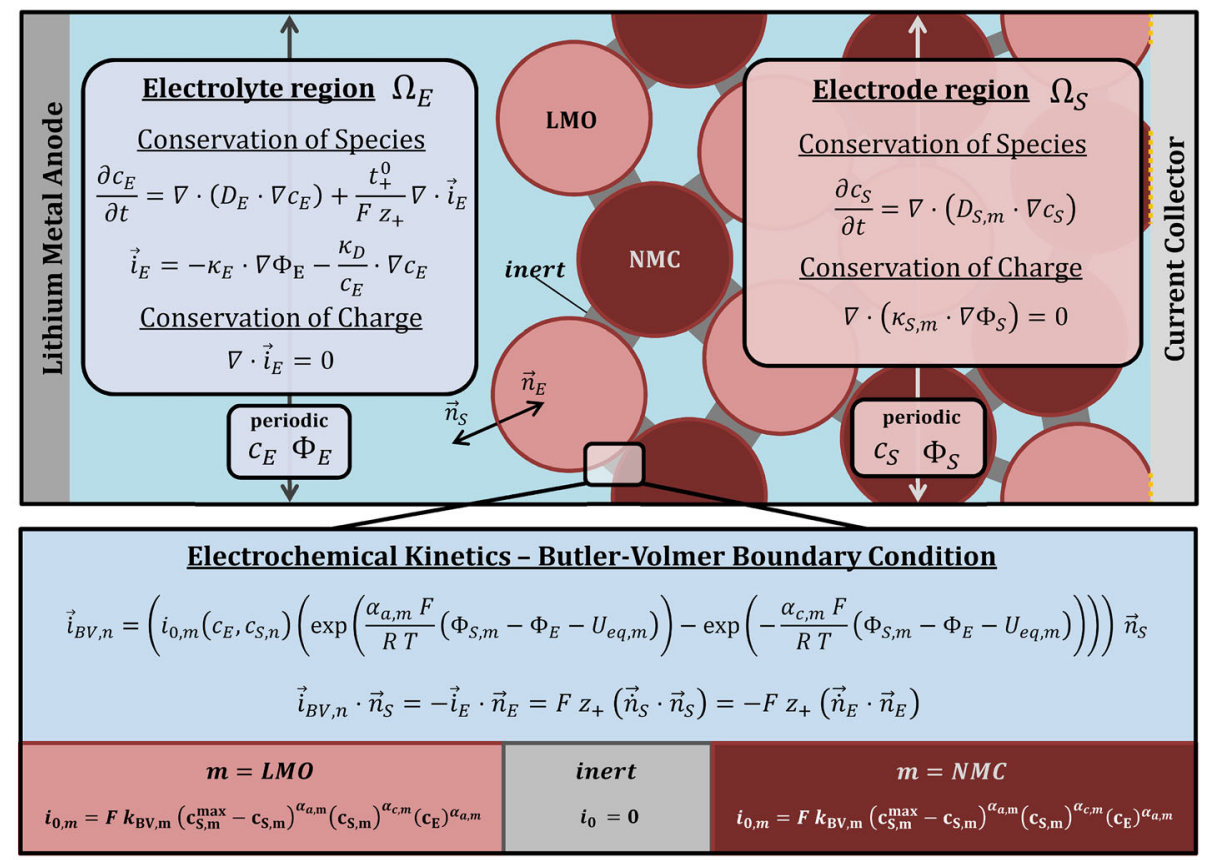

FIGURE 1 Illustration of the particle resolved electrochemical model [Colour figure can be viewed at wileyonlinelibrary.com] 
the ionic conductivity, the transference number of the lithium ions, and the interdiffusion coefficient of lithium ions within a mixture of dissociated salt and solvent. Furthermore, $T$ denotes the absolute temperature, $R$ the universal gas constant, and $F$ the Faraday constant, respectively. Moreover, the transport properties $\kappa_{E}$ and $D_{E}$ depend on the local concentration of lithium ions within the electrolyte. For this purpose, polynomial fits, based on the findings of Less et $\mathrm{al}^{19}$ and repeated elsewhere, ${ }^{22}$ are used.

The separator is assumed to be of constant isotropic and location-independent structural properties, which makes the model of effective transport properties applicable. Within the separator's subdomain, the interdiffusion coefficient $D_{E}^{\text {Sep }}$ and the ionic conductivity $\kappa_{E}^{\text {Sep }}$ are evaluated as follows ${ }^{25,26}$ :

$$
\begin{gathered}
D_{E}^{S e p}=D_{E}\left(c_{E}\right) \frac{\epsilon_{S e p}}{\tau_{S e p}}, \\
\kappa_{E}^{S e p}=D_{E}\left(c_{E}\right) \frac{\epsilon_{S e p}}{\tau_{S e p}} .
\end{gathered}
$$

In Equations (5) and (6), $\epsilon_{S e p}$ and $\tau_{S e p}$ denote the separator's porosity and tortuosity, which is set to values representative for a standard Celgard 2400 porous separator within the separator's subdomain. Outside the separator's region, its values are set to unity.

In order to realize the coupling between the solid electrode and the liquid electrolyte subdomains, a Butler-Volmer type electrochemical kinetics relation and continuity conditions are used. ${ }^{23}$

$$
\begin{aligned}
i_{B V, m}= & i_{0, m}\left(\exp \left(\frac{\alpha_{a, m} F}{R T}\left(\Phi_{S}-\Phi_{E}-U_{e q, m}\right)\right)\right. \\
& \left.-\exp \left(\frac{\alpha_{c, m} F}{R T}\left(\Phi_{S}-\Phi_{E}-U_{e q, m}\right)\right)\right) \\
i_{0 m}=k_{B V, m} F & \left(c_{S, m}^{\max }-\left.c_{S, m}\right|_{\Gamma_{S, E}}\right)^{\alpha_{a, m}}\left(\left.c_{S, m}\right|_{\Gamma_{S, E}}\right)^{\alpha_{c, m}}\left(\left.c_{E}\right|_{\Gamma_{E, S}}\right)^{\alpha_{a, m}}
\end{aligned}
$$

$$
\begin{aligned}
\vec{i}_{B V} \cdot \vec{n}_{S} & =-\overrightarrow{i_{E}} \cdot \vec{n}_{E}=F z_{+}\left(\overrightarrow{\dot{n}}_{S} \cdot \vec{n}_{S}\right) \\
& =-F z_{+}\left(\overrightarrow{\dot{n}}_{S} \cdot \vec{n}_{E}\right) .
\end{aligned}
$$

Here, $\vec{n}_{S}$ and $\vec{n}_{E}$ denote the outward directed normal vectors of the solid electrode $\Omega_{S}$ and the electrolyte subdomain $\Omega_{E}$, respectively. In addition to that, $\alpha_{a}$ and $\alpha_{c}$ symbolize the anodic and cathodic apparent transfer coefficients. ${ }^{23}$ Equal to Hutzenlaub et al, ${ }^{27}$ Equations (7), (8), and (9) are implemented as Neumann boundary conditions on the surface of the active material particles. In order to account for different active materials within the blended electrode, its varying material properties have to be considered in Equation (7) and (8). In this context, index $m$ stands for the active materials under consideration, which in the scope of this contribution is LMO and NMC. Moreover, $c_{S, m}^{\max }$ denotes the maximum stoichiometric lithium concentration of the specific active material and $k_{B V, m}$ a material-dependent constant. For the open-circuit potential of the different materials $U_{e q, m}$, steady analytical functions from literature are used.

On the interface between the passive material fraction and the electrolyte, the intercalation flux density $\overrightarrow{i_{B V}} \cdot \overrightarrow{n_{S}}$ is assumed to be zero. The electrochemical reactions occurring on the surface of the lithium anode are presumed to be fast so that the electrical potential can be set to zero. In order to fulfill the conservation of charge condition between the positive and the negative electrode, the lithium flux $\overrightarrow{i_{E}}$ at the lithium anode is set according to the average current density on the cathode current collector. At the cathode's current collector, the ionic current density $\overrightarrow{i_{E}}$ is set to zero.

\subsection{Model parameters}

Figure 2 shows the implemented equilibrium potentials for LMO and NMC. Here, the depth of discharge (DOD) is calculated individually for each of the active materials. For LMO, a fit of the open-circuit potential $U_{e q, L M O}$ reported by Doyle et $\mathrm{al}^{25}$ is used. For the NMC material, the open-circuit potential is fitted to experimental data reported by Fang et al. ${ }^{28}$ As can be seen in Figure 2, the curves of the equilibrium potential of both active materials show different local slopes. While NMC has an approximately constant negative slope over the entire range of discharge states, LMO basically shows two regions of large negative slopes: one in the beginning and one at the end of discharging. As will be shown later, this characteristic directly influences the intercalation kinetics on the particulate level.

The parameters used to describe the transport properties of the two active materials are summarized in Table 1. It was shown that the electrical conductivity $\kappa_{S}$ may considerably influence the performance of the simulated half-cells if its value is too low. ${ }^{22}$ According to these previous results, $\kappa_{S}=20 \mathrm{~S} \mathrm{~m}^{-1}$ is regarded as sufficient. The electrical conductivity was set as uniform value for the complete electrode subdomain $\Omega_{S}$. To suppress lithium diffusion within the inert material subdomain $\Omega_{S}^{P}$, its local diffusion coefficient is set to a value of $D_{S}^{P}=10{ }^{20} m^{2} s^{1}$. 
FIGURE 2 Representation of the implemented equilibrium potentials $U_{e q}$ for $\mathrm{LMO}^{25}$ and $\mathrm{NMC}^{28}$ [Colour figure can be viewed at wileyonlinelibrary.com]

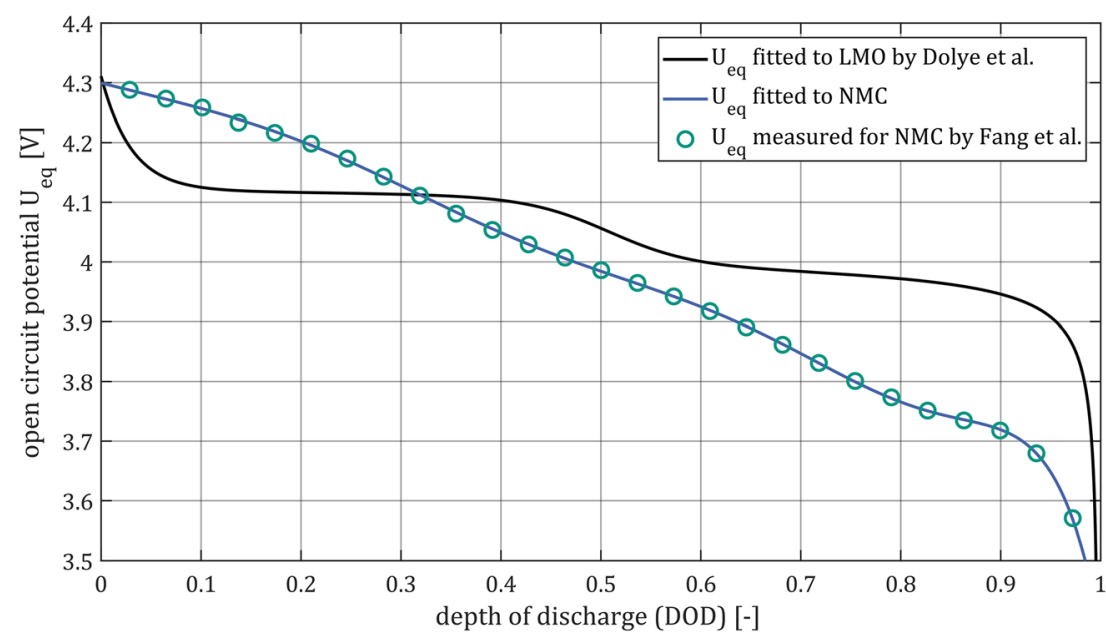

conditions at a constant temperature of $T=298 \mathrm{~K}$ are presumed for all simulations. the active material particles is assumed to be per-particle constant and is chosen such that the overpotential at the active material particles' solid-electrolyte interface for the given initial electrode potential vanishes.

The intercalation rate constants $k_{B V, m}$ of the different active materials are determined experimentally for a commercially available lithium-ion battery. The methodology that was used to determine this material parameter is based on a combination of impedance spectroscopic measurements with data obtained from microstructure reconstructions ${ }^{33-35}$ and was not part of this work.

The initial lithium concentration within the electrolyte phase is set to $1000 \mathrm{~mol} \mathrm{~m}^{-3}$ and assumed to be uniform. Additionally, the initial electrical potential within the electrolyte is set to a uniform value of zero Volts. Consonant to the study of Less et al, ${ }^{19}$ the transference number is assumed to be $t_{+}^{0}=0.4$. Furthermore, according to the studies of Thorat et al and Djian et al, ${ }^{26,36}$ the separators porosity and tortuosity values are chosen as $\epsilon_{\text {Sep }}=0.32$ and $\tau_{\text {Sep }}=$ 5.3. Furthermore, isothermal operation

TABLE 1 Material parameters for LMO and NMC

\begin{tabular}{|c|c|c|}
\hline Parameter & LMO & NMC \\
\hline $\begin{array}{l}\text { Diffusion } \\
\quad \text { coefficient } D_{S}^{A} m\end{array}$ & $\begin{array}{l}2.2 \cdot 10^{-13} \mathrm{~m}^{2} \mathrm{~s}^{-1} \\
\text { from the study } \\
\text { of Barker et } \mathrm{al}^{29}\end{array}$ & $\begin{array}{l}2.0 \cdot 10^{-14} \mathrm{~m}^{2} \mathrm{~s}^{-1} \\
\text { from the study } \\
\text { of Fang et } \mathrm{al}^{28}\end{array}$ \\
\hline $\begin{array}{l}\text { Intercalation rate } \\
\text { constant } k_{B V, m}\end{array}$ & $\begin{array}{c}2.71 \cdot 10^{-9} \mathrm{~m}^{2.5} \\
\mathrm{~mol}^{-0.5} \mathrm{~s}^{-1}\end{array}$ & $\begin{array}{c}9.25 \cdot 10^{-9} \mathrm{~m}^{2.5} \\
\mathrm{~mol}^{-0.5} \mathrm{~s}^{-1}\end{array}$ \\
\hline $\begin{array}{l}\text { Stoichometric } \\
\text { maximum } \\
\text { concentration } c_{S, m}^{\max }\end{array}$ & $\begin{array}{l}22.9 \mathrm{kmol} \mathrm{m}^{-3} \\
\text { from the study } \\
\text { of Zhang et } \mathrm{al}^{30}\end{array}$ & $\begin{array}{l}49.5 \mathrm{kmol} \mathrm{m}^{-3} \\
\text { from the study } \\
\text { of Fang et } \mathrm{al}^{28}\end{array}$ \\
\hline Specific density $\rho_{S, m}$ & 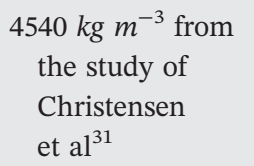 & $\begin{array}{l}4770 \mathrm{~kg} \mathrm{~m}^{-3} \text { from } \\
\text { the study of de } \\
\text { Vasconcelos } \\
\text { et } \mathrm{al}^{32}\end{array}$ \\
\hline
\end{tabular}

\section{ELECTRODE STRUCTURES}

The basis for the numerical investigations are five electrode structures consisting of varying proportions of LMO and NMC. Those electrodes that consist of only one active material component are referred to as LMO or NMC reference electrode. The structural parameters of the particulate electrode structures are summarized in Table 2.

As shown in a previous publication, ${ }^{21}$ the size of the active material particles is related to the macroscopic performance of a half-cell. In order to ensure the comparability of the investigated mixed material electrodes, the particle sizes of the considered active materials are subject to a monomodal distribution with a small spread. Hence, the underlying particle size distribution results in a comparable volume-specific active surface of the considered electrode structures (see Table 2). Furthermore, the small scattering of the areic nominal capacity of the half-cells of $\bar{K}_{A}=(1,97 \pm 0,08) m A h \mathrm{~cm}^{2}$ leads to matching integral currents at the cathode's current collector for given galvanostatic discharge rates. Consequently, the comparability of the half-cells at identical discharge rates is given.

The decreasing layer thickness of the electrodes with increasing proportion of NMC is due to the higher stoichiometric maximum lithium concentration of NMC compared with LMO. Because of similar specific densities of both materials (see Table 1), an increase of the NMC fraction leads to a rise of the nominal gravimetric capacity of the half-cells. The gravimetric nominal capacities given in Table 1 are based on the mass of the active material. 
TABLE 2 Structural parameters of the blended electrodes

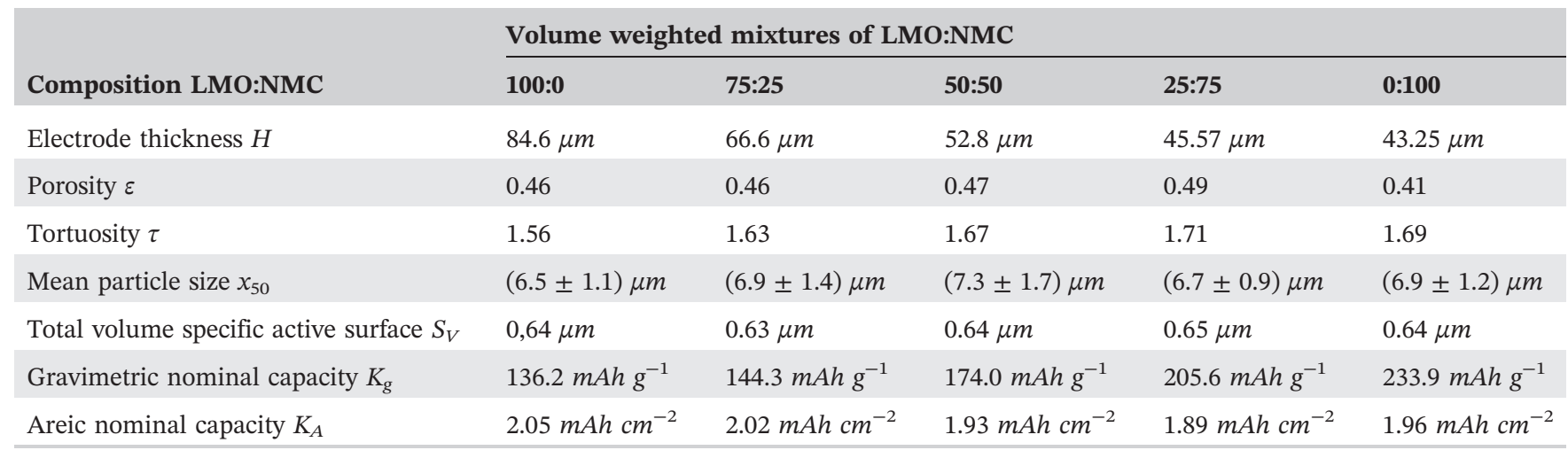

As experimentally shown by Bauer et $\mathrm{al}^{37}$ and in accordance to numerical results of a previous contribution, ${ }^{21}$ the influence of the electrode structure on the macroscopic performance is more pronounced for uncalendered electrodes. For this reason, in this contribution, only uncompressed electrodes are considered, whose porosity values (see Table 2) are in agreement with published values of uncalendered electrodes. ${ }^{37-39}$ The periodic structure of the blended electrode with a volumetric ratio of $50 \%_{L M O}: 50 \%_{N M C}$ is exemplarily depicted in Figure 3.

The simulations have been performed in parallel on high-performance computer clusters available at Karlsruhe Institute of Technology. Depending on the number of finite volume elements of the resulting meshes (up to 15 Mio.), the calculations are performed on up to 224 cores, which resulted in an approximate computation time of 3 days for each simulation.

\section{RESULTS AND DISCUSSION}

In this contribution, the focus is on the simulation of galvanostatic discharge processes. In this context, at a discharge rate of $1 \mathrm{C}$, the current at the current collector is adjusted such that the complete discharging of the considered half-cell takes a time period of 1 hour. In order to facilitate the comparability of the different electrodes in terms of a time-dependent discharge behavior, the $D O D$ is used. The $D O D$ represents a dimensional discharge time and is calculated as follows:

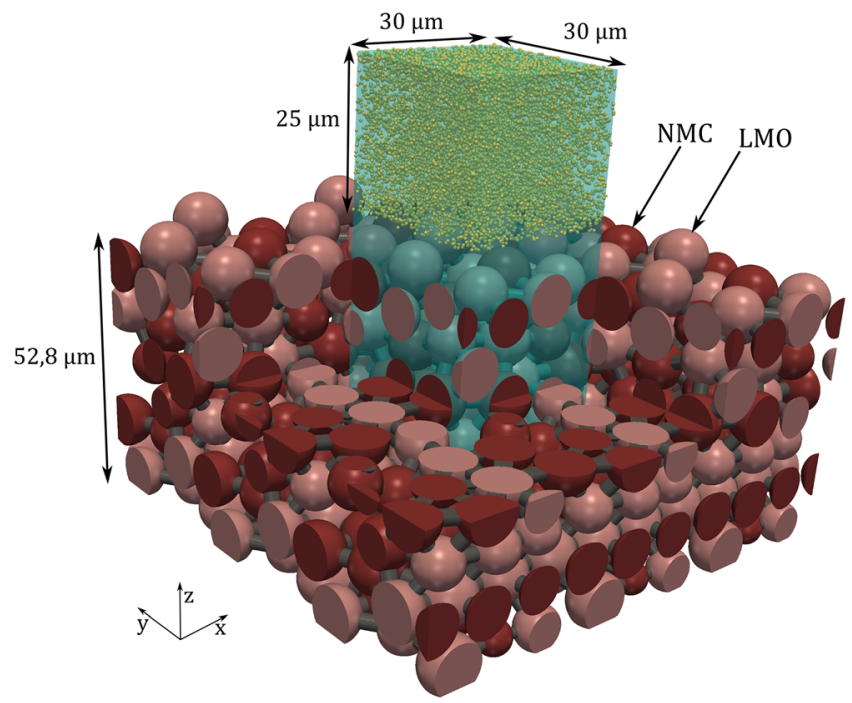

FIGURE 3 Computer generated, periodically extended electrode structure consisting of a physical volumetric mixture of $50 \%_{L M O}: 50 \%_{N M C}$ [Colour figure can be viewed at wileyonlinelibrary.com]

\subsection{Macroscopic evaluation of the numerical results}

Figure 4 shows the simulated half-cell potentials of the investigated blended electrodes at galvanostatic discharging for two different discharge rates. In addition, the implemented equilibrium potentials for the two active materials LMO and NMC, according to Newman ${ }^{25}$ and Fang et $a{ }^{28}$ are plotted.

$$
D O D=1-\frac{\int_{\Omega_{S, N M C}}\left(c_{S, N M C}(t)-c_{S, N M C}^{0}\right) d \Omega_{S, N M C}+\int_{\Omega_{S, L M O}}\left(c_{S, L M O}(t)-c_{S, L M O}^{0}\right) d \Omega_{S, L M O}}{\int_{\Omega_{S, N M C}}\left(c_{S, N M C}^{\max }-c_{S, N M C}^{0}\right) d \Omega_{S, N M C}+\int_{\Omega_{S, L M O}}\left(c_{S, L M O}^{\max }-c_{S, L M O}^{0}\right) d \Omega_{S, L M O}} .
$$



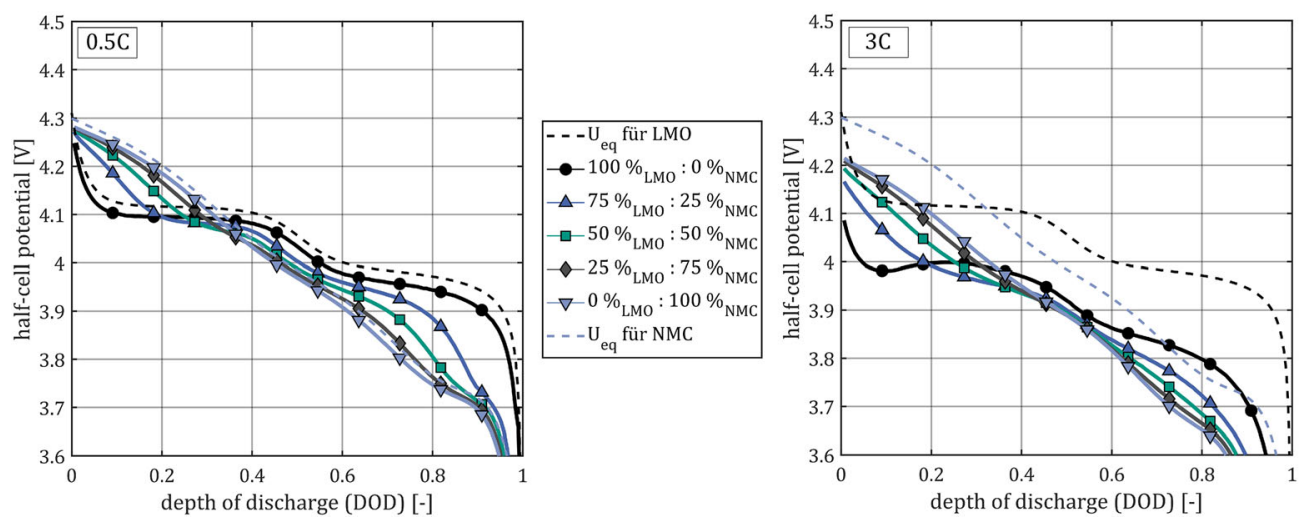

FIGURE 4 Simulated half cell potential for varying galvanostatic discharge rates of $0.5 \mathrm{C}$ (left) and 3C (right) [Colour figure can be viewed at wileyonlinelibrary.com]

The comparison of the potential curves in Figure 4 shows a shift of the simulated half-cell potentials toward lower values for increasing discharge rates. This is due to the overpotential at the active particle surface, which increases at increasing galvanostatic discharge rates. Furthermore, the comparison of the LMO and the NMC reference electrode at a discharge rate of $3 \mathrm{C}$ reveals that LMO shows a $16 \%$ higher mean deviation from its open circuit potential $U_{e q, L M O}$ compared with NMC. This correlates with the rate constants of the intercalation reaction $k_{B V, m}$, which is assumed to be lower by a factor of 3.4 for LMO compared with NMC (see Table 1). The latter results in an increase of the local overpotential for LMO at a given discharge rate and consequently the macroscopically measurable half-cell voltage is reduced.

Particularly at a low discharge rate of $0.5 \mathrm{C}$ (Figure 4, left), the discharge curves of the LMO or NMC reference electrode mark an envelope for the series of investigated blended electrodes. At the same time, Figure 4 shows that, depending on the composition of the electrodes, the simulated half-cell potentials are either closer to one or the other reference electrode. Because of the lower mean half-cell potentials for increasing discharge rates, this effect is less pronounced for $3 \mathrm{C}$ (see Figure 4, right).

These results for the low discharge rate are in agreement with findings of $\mathrm{Lu}$ et $\mathrm{al},{ }^{14}$ who developed a model for the prediction of the equilibrium voltage curve of blended electrodes. This model is based on the assumption that kinetic effects, such as local overpotentials, play a minor role in the equilibrium operation of a half-cell. As a consequence, with knowledge of the equilibrium potential curves of the pure active materials and the material proportions of a given blended electrode, its open circuit potential is predictable by means of superposition. This hypothesis was also experimentally confirmed by Lu et al. ${ }^{14}$

Figure 5 shows the utilizable capacity of the simulated half-cells with varying composition as a function of the galvanostatic discharge rate. The end of the discharge process is assumed to be reached, when the half-cell potential drops below $3.6 \mathrm{~V}$. The utilizable capacities shown in Figure 5 are referenced to the theoretical maximum capacities of the active material components at $3.6 \mathrm{~V}$.
FIGURE 5 Relation between the composition of the blended electrodes and its utilizable capacity at different galvanostatic discharge rates [Colour figure can be viewed at wileyonlinelibrary.com]

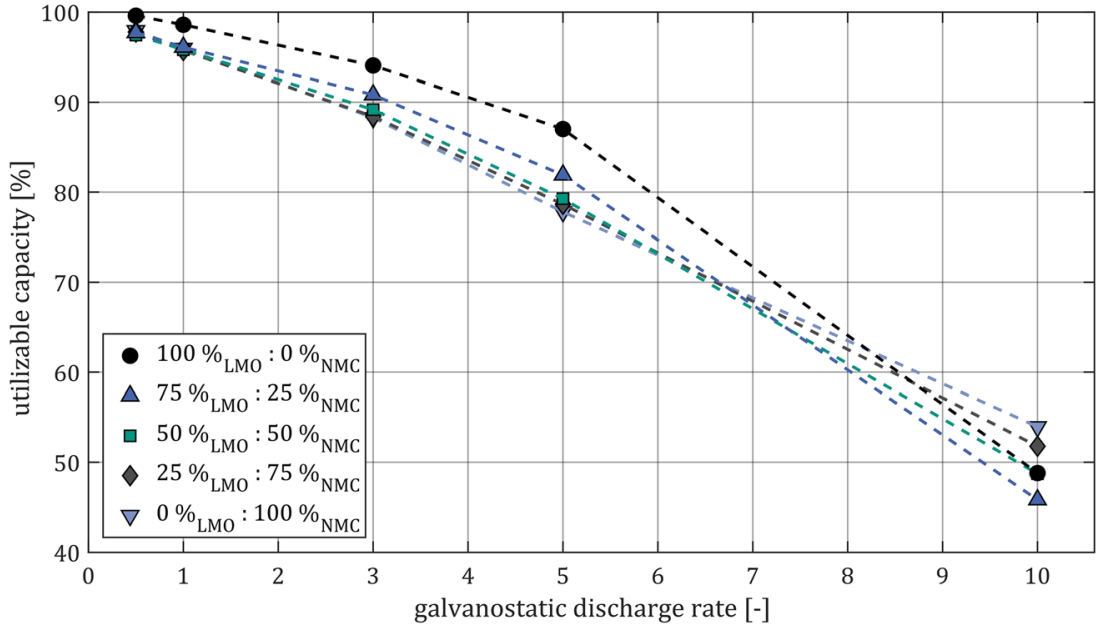


The blended electrodes show only slight differences less than $4.3 \%$ in the utilizable capacity at low discharge rates less than 1C. Furthermore, it can be seen that for discharge rates up to $5 \mathrm{C}$, the utilizable capacity of the simulated half-cells increases with an increasing fraction of LMO. This is due to the higher mean half-cell potential of LMO compared to the NMC. Therefore, the end of a discharge cycle is achieved at higher DOD values (see Figure 4).

At a discharge rate of $10 \mathrm{C}$, however, this relationship is reversed. As can be taken from Figure 5, those blended electrodes with a higher content of NMC show better performance characteristics. This is due to the rate constant of the intercalation reaction $k_{B V, m}$ which is lower for LMO compared with NMC (see Table 1). At a given discharge rate, this results in a higher overpotential on the surface of the LMO component compared with the NMC component that is associated with a reduction of the mean half-cell potential of the LMO-rich half-cells. When a critical discharge rate is exceeded, the difference between the mean equilibrium potentials of LMO and NMC is overcompensated, which manifests macroscopically in a lower utilizable capacity.

\subsection{Evaluation of the numerical results on the particle scale}

Figure 6 exemplarily depicts the spatial lithium distribution for the blended electrode with a volumetric mixture of both materials of $50 \%_{L M O}: 50 \%_{N M C}$ over the course of one discharge cycle. The lithium concentration is normalized to the stoichiometric maximum concentration of the respective active material component. The electrode microstructure is identical to the periodically extended particulate structure shown in Figure 3. The labeling of the two active material components in Figure 6 is for orientation.

The time course of the illustrated galvanostatic discharge process makes the different material behavior of the active components visible. At the beginning of the simulated discharge cycle, the relative lithium concentration of the NMC particles is increased compared with the LMO particles. In the further course of the discharge process, at $D O D=0.4$, it can be seen that the relative concentration differences between the two materials balance out. From $D O D=0.6$ on, the relationship described above inverts, and the relative lithium concentration of the LMO particles remains higher than that of the NMC particles until the end of the simulated discharge process is reached.

The qualitative statements from Figure 6 can be quantified using the illustration in Figure 7. The graphs show the mean $D O D, D O D_{m}$, for the active material components m with $m=L M O$ or $m=N M C$ over entire half-cell's averaged $D O D$ for the investigated compositions of the blended electrodes. In the cases of the LMO or NMC reference electrodes, the averaged discharge states of the individual components are identical to the state of discharge of the entire half-cell. Consequently, their curves coincide with the first bisector and are not shown here for simplicity.

In accordance to the qualitative analysis of Figure 6, the discharge process in Figure 7 can be divided into two sections. From the beginning of the discharge up to a critical $D O D, D O D_{k r i t}$, the NMC particles have a higher average DOD compared to the LMO particles. After this critical $D O D$, the latter mentioned correlation is reversed.

As can be seen from the graph in Figure 7, higher discharge rates result in a shift of the curve intersection toward larger depths of discharge. At the same time, the curves are less contoured so that the differences in material behavior become blurred.

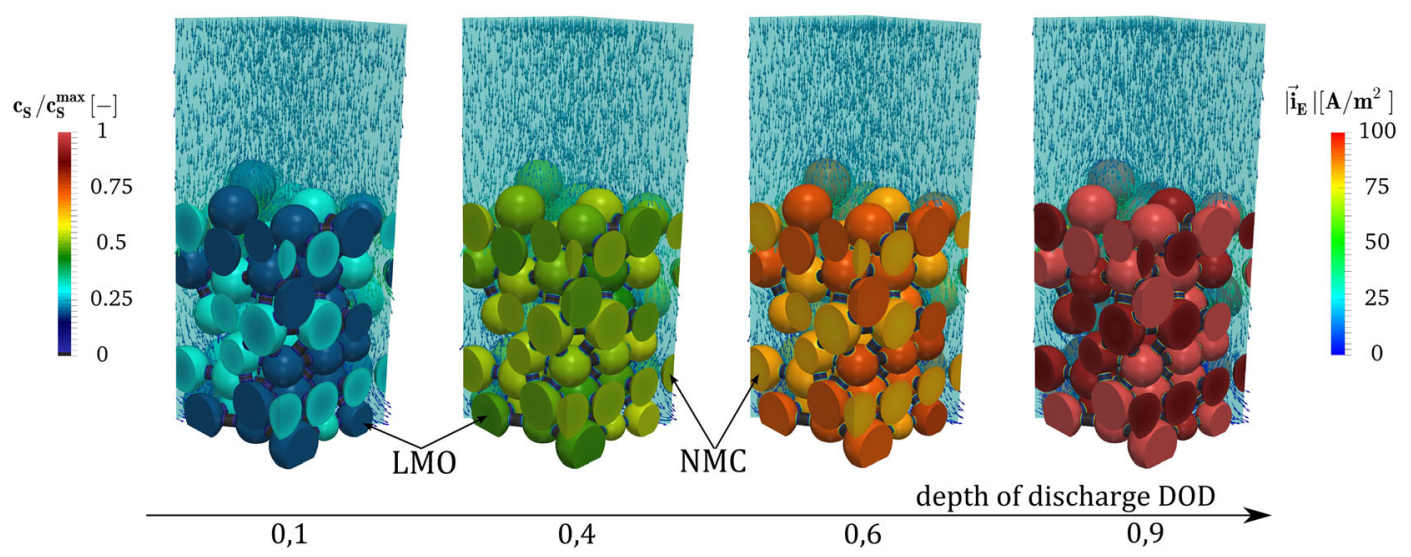

FIGURE 6 Spatially resolved representation of the lithium distribution within the blended electrode depicted in Figure 3, from left to right: course of a galvanostatic discharge cycle at a discharge rate of $1 \mathrm{C}$ [Colour figure can be viewed at wileyonlinelibrary.com] 

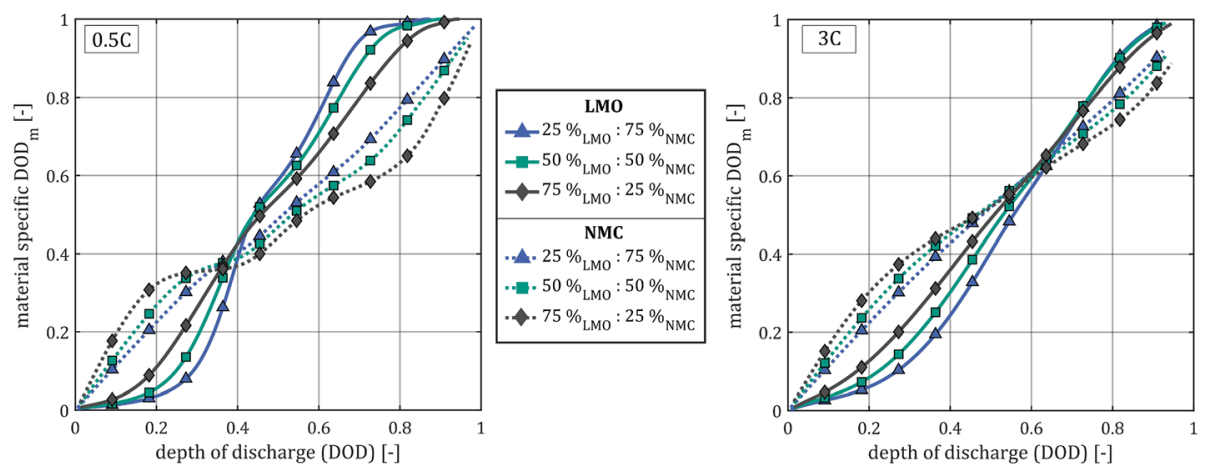

FIGURE 7 Component wise representation of the depth of discharge for the active components $m \quad$ LMO or $m \quad$ NMC over the overall depth of discharge (DOD) of the electrode. Considered are galvanostatic discharge processes at $0.5 \mathrm{C}$ (left) and $3 \mathrm{C}$ (right) [Colour figure can be viewed at wileyonlinelibrary.com]

Furthermore, it can be seen from Figure 7 that the LMO component reaches a higher $D O D_{m}$ in comparison to NMC, independent of the numerically applied discharge rate. This can be explained by the higher mean equilibrium potential of LMO and is therefore consistent with the results of Chikkannanavar et al. ${ }^{1}$ Corresponding to their study, ${ }^{1}$ the necessity of a higher cyclic stability of LMO compared with NMC can be derived.

In Figure 8, the fraction of the intercalation current $\Psi_{L M O}$ is calculated as follows:

$$
\Psi_{L M O}=\frac{\int_{\Gamma_{S E, L M O}}\left(\vec{i}_{B V} \cdot \vec{n}_{S}\right) d S}{\int_{\Gamma_{S E, L M O}}\left(\vec{i}_{B V} \cdot \vec{n}_{S}\right) d S+\int_{\Gamma_{S E, N M C}}\left(\vec{i}_{B V} \cdot \vec{n}_{S}\right) d S} .
$$

In addition, the closing condition applies

$$
\Psi_{N M C}=1-\Psi_{L M O}
$$

which enables the calculation of the fraction of the intercalation current for NMC.
Figure 8 shows that the fraction of the intercalation current is subject to temporal variations during a galvanostatic discharge process. This behavior is independent of the simulated discharge rate, but the differences are more pronounced at low discharge rates. Furthermore, it can be seen in Figure 8 that the proportion of the intercalation current absorbed by an active material component is dependent on the active material composition of the electrode. Because of the volumetrically weighted material composition and the different volumetric capacity of the active materials, the time average values of the intercalation currents do not represent the respective mixing ratios.

At the low discharge rate of $0.5 \mathrm{C}$ (see Figure 8, left), it can be seen that in the region of $D O D<0.2$, and thus, at high half-cell potentials, the intercalation current is mainly absorbed by the NMC component. This characteristic, which can be seen on the particulate level, can be traced back to the open circuit potential curves of LMO and NMC (see Figure 2). For $D O D<0.2$, the equilibrium potential of NMC has a lower slope compared with LMO. Accordingly, small concentration changes on the particle surface of the LMO component lead to large changes in
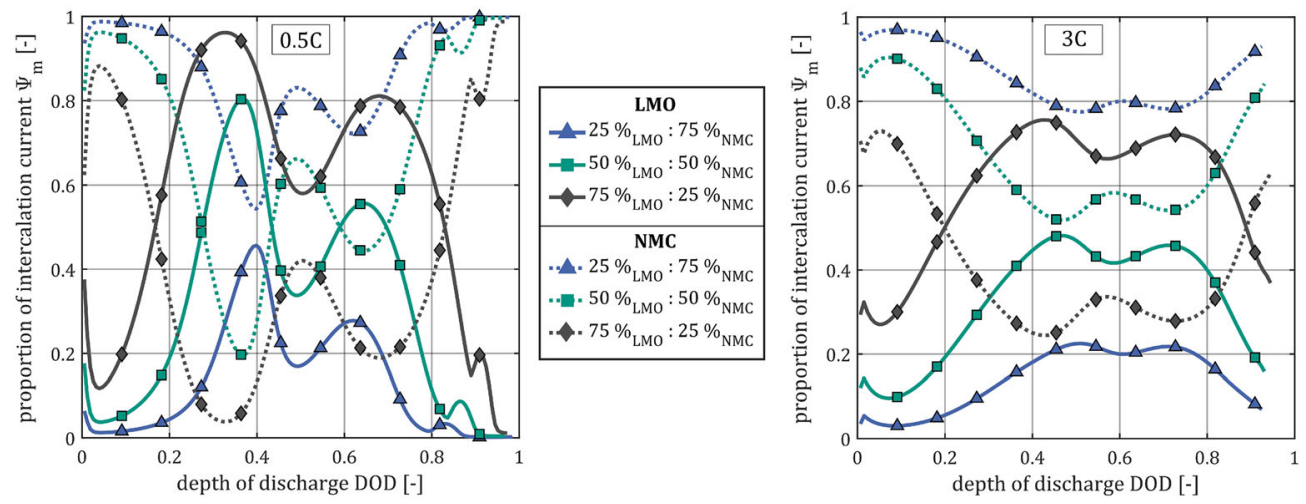

FIGURE 8 Proportion of intercalation current $\Psi_{m}$ for each of the active components $m$ for a simulated galvanostatic discharge cycle at discharge rates of $0.5 \mathrm{C}$ (left) and $3 \mathrm{C}$ (right) [Colour figure can be viewed at wileyonlinelibrary.com] 
its equilibrium potential. Consequently, NMC shows a higher lithium uptake potential compared with LMO, which results in increased local intercalation flux densities on the surface of the NMC component.

In the region of $0.2<D O D<0.8$, there is a shift in the average intercalation current from the NMC to the LMO component. In this range, the LMO's equilibrium potential curve has smaller slope compared with NMC, resulting in a reversal of the previously observed distribution of intercalation current. Furthermore, for LMO at $D O D \approx 0.5$, a local minimum of the fraction of the intercalation current is recognizable. This correlates with a slightly more negative slope of the equilibrium potential of LMO, which connects the two nearly constant plateaus of the equilibrium potential.

This result is qualitatively consistent with numerical results from Albertus et $\mathrm{al}^{9}$ who examined blended electrodes composed of different amounts of LMO and $\mathrm{LiNi}_{0.8} \mathrm{Co}_{0.15} \mathrm{Al}_{0.05} \mathrm{O}_{2}$ (NCA). The comparison of the numerical results is possible in a sense that the equilibrium potential profiles of NMC and NCA match qualitatively. NCA has an approximately $0.15 \mathrm{~V}$ lower mean equilibrium potential with respect to NMC. Compared to the absolute half-cell potential, this difference in the equilibrium potential can be stated as negligible for a qualitative comparison of the results.

In the last part of the discharge process at $D O D>0.8$, the equilibrium potential of LMO drops sharply compared with NMC so that its activity within the blend electrode decreases, which is consistent with the results of Albertus et al. ${ }^{9}$

At the same time, the maximum DOD of the LMO component is reached (see Figure 7). The temporal variation in the distribution of the intercalation current between the active materials is the reason for the contoured plot of the material-specific DODs at $0.5 \mathrm{C}$, observed in Figure 7 on the left.
Because of the described temporal variation of the intercalation current between both active components, operation of the half-cell outside $0.2<D O D<0.8$ is not recommended. That is because outside of this operating window, the NMC component absorbs a large part of the intercalation current. The latter can be expected to lead to an increased aging of this kind of active material, thus indicating a shortened cycle life of the half-cell. ${ }^{40}$

The dependencies described for $0.5 \mathrm{C}$ are in the same way qualitatively valid for the discharge rate of $3 \mathrm{C}$ (see Figure 8, right). However, the curves of the fraction of the intercalation current appear to be smoothened. This tendency is also consistent with numerical results of Albertus et al. ${ }^{9}$ At increasing discharge rates, the magnitude of the overpotential increases, which reduces the influence of the equilibrium potential of both active materials.

Figure 9 shows the relative maximum concentration differences for the active material components $\Delta c_{S, N M C}$ and $\Delta c_{S, L M O}$ within the blended electrode structures during a simulated galvanostatic discharge process. The maximum concentration difference is related to the respective stoichiometric maximum concentration and is exemplarily calculated for NMC as follows:

$$
\Delta c_{S, N M C}(t)=\max \left(\frac{c_{S}(t)}{c_{S, N M C}^{\max }}\right)-\min \left(\frac{c_{S}(t)}{c_{S, N M C}^{\max }}\right) \text { in } \Omega_{S}^{N M C} .
$$

Because of the dissimilarities in the relative concentration differences within the LMO particles compared with the NMC particles, which differ by about an order of magnitude, the plot in Figure 9 is made using two different scales. The difference is due to the diffusion coefficient for NMC, which is about one order of magnitude lower than that for LMO (see Table 1).
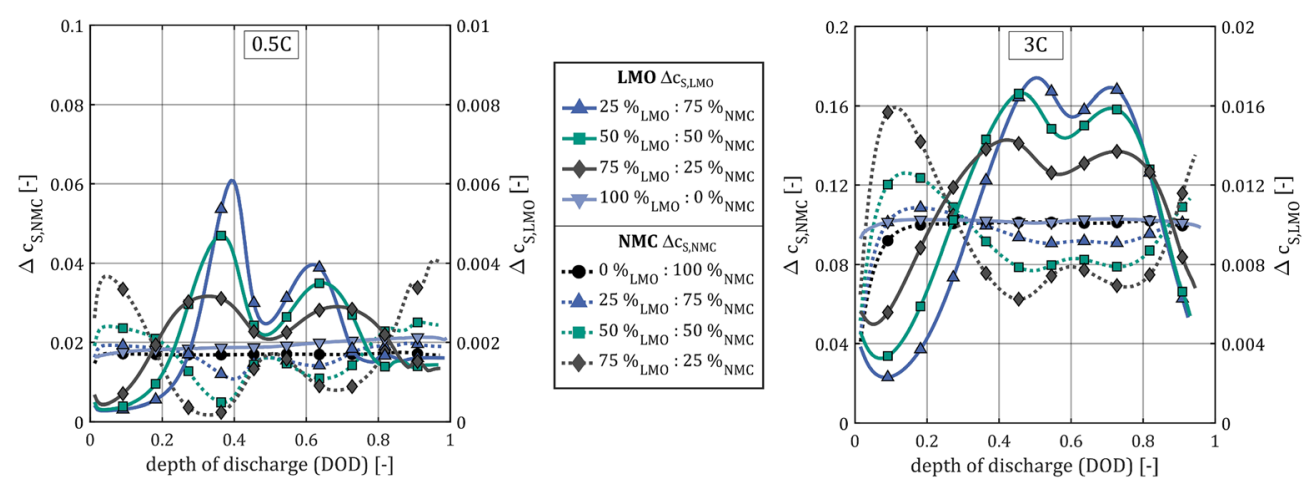

FIGURE 9 Relative maximum concentration differences of LMO and NMC for a simulated discharge cycle at $0.5 \mathrm{C}$ (left) and 3C (right) [Colour figure can be viewed at wileyonlinelibrary.com] 
This leads to lower concentration gradients within the LMO component at a given intercalation current density on the active particle's surface. Because of the consideration of the maximum concentration differences in Figure 9, each value is representative for the largest particle of the two active materials within the electrode structures. Because of the small spread of particle sizes, however, the differences within a class of active material are negligible.

Consonant to the analytical solution of the transient diffusion equation for single spherical particles with a constant flux boundary condition, ${ }^{41}$ at the beginning of the discharge process, a steep rise of the curves is observed for the investigated LMO or NMC reference electrodes. This trend is then followed by a plateau of the concentration difference. This characteristic can be observed independently of the applied discharge rate. However, at higher discharge rates, larger maximum concentration differences occur, which are also reached at later times.

The time dependency of the intercalation current (see Figure 8) causes temporal maxima of the maximum concentration differences for the investigated blended electrodes. In this context, it can be extracted from Figure 9 that, regardless of the discharge rate, a shift in the intercalation current toward LMO is associated with a reduction of the resulting maximum concentration differences within the NMC material. This is pronounced for the low discharge rate of $0.5 \mathrm{C}$ at $D O D \approx 0.35$. This also shows that the maximum concentration difference within the NMC material can be reduced by increasing the proportion of LMO. Considering the $75 \%_{L M O}: 25 \%_{N M C}$ electrode, it can be seen that, within the defined operating window of $0.2<D O D<0.8$, the time averaged maximum concentration difference of the NMC particles can be reduced by $46 \%$ compared with the NMC reference electrode.

At a discharge rate of $3 \mathrm{C}$, variations in the maximum concentration differences between the active blended electrodes are less pronounced. This is due to the lower temporal variation of the intercalation current between the active components as discussed before. Accordingly, the temporal average maximum concentration differences of the NMC component within the considered blended electrode is reduced to $21 \%$ compared with the NMC reference electrode.

According to Bohn et $\mathrm{al}^{42}$ the maximum radial mechanical stress component within an active material particle is proportional to the change in the lithium concentration. Analogous the maximum values of the concentration differences shown in Figure 9 give a first indication of the expectable diffusion-induced mechanical stresses in the interior of the active material.
The formation of diffusion-induced mechanical stresses within the active material is one of the reasons for its mechanical degradation and the associated measurable loss of capacity. ${ }^{43}$ In this context, a large number of numerical investigations on single active material particles show that the magnitude of the mechanical stresses depend on the shape and size of the particles ${ }^{30,44,45}$ and can thereby exceed the tensile strength of the material. $^{46,47}$ This is particularly the case when it comes to phase separation processes. ${ }^{42,45,48}$

The results presented in Figure 9 suggest a reduction of the diffusion-induced mechanical stresses within the NMC particles because of the addition of LMO. Assuming similar mechanical properties of both materials, reduced mechanical stress on the NMC material is expected, resulting in an improved cycle life of the cells. In addition to that, the numerical results indicate, that the half-cells' cyclic aging resistance is further enhanced by obeying the operating window of $0.2<D O D<0.8$.

\subsection{Numerical investigation of the particle arrangement}

The following discussion deals with the question on how the arrangement of the two active components LMO and NMC within a blended electrode influences its electrochemical performance. The basis for this investigation is the electrode structure of the blend electrode shown in Figure 3 with a volumetric fraction of both active components of $50 \%_{L M O}: 50 \%_{N M C}$. Accordingly, the structural parameters of the electrodes considered below are identical and summarized in Table 2 .

The random arrangement of both active materials represents the reference state and is shown in the middle of Figure 10. In contrast, there are two layered arrangements, wherein the active components are located in discrete regions. In the electrode structure designated as "layered arrangement A" the LMO component is located exclusively in the upper region, ie, in the vicinity of the separator. In this structure, the NMC material is located close to the current collector. For the structure denoted as "layered arrangement B" this correlation analogously inverse (see Figure 10).

Because of the matching geometric basis of the blended electrodes shown in Figure 10, their nominal capacity is identical. Consequently, the comparability of the considered electrode structures with regard to the calculated, integral currents at a given galvanostatic discharge rate is given.

The distribution of the magnitude of the ionic current density within electrolyte (see Figure 11) is evaluated 


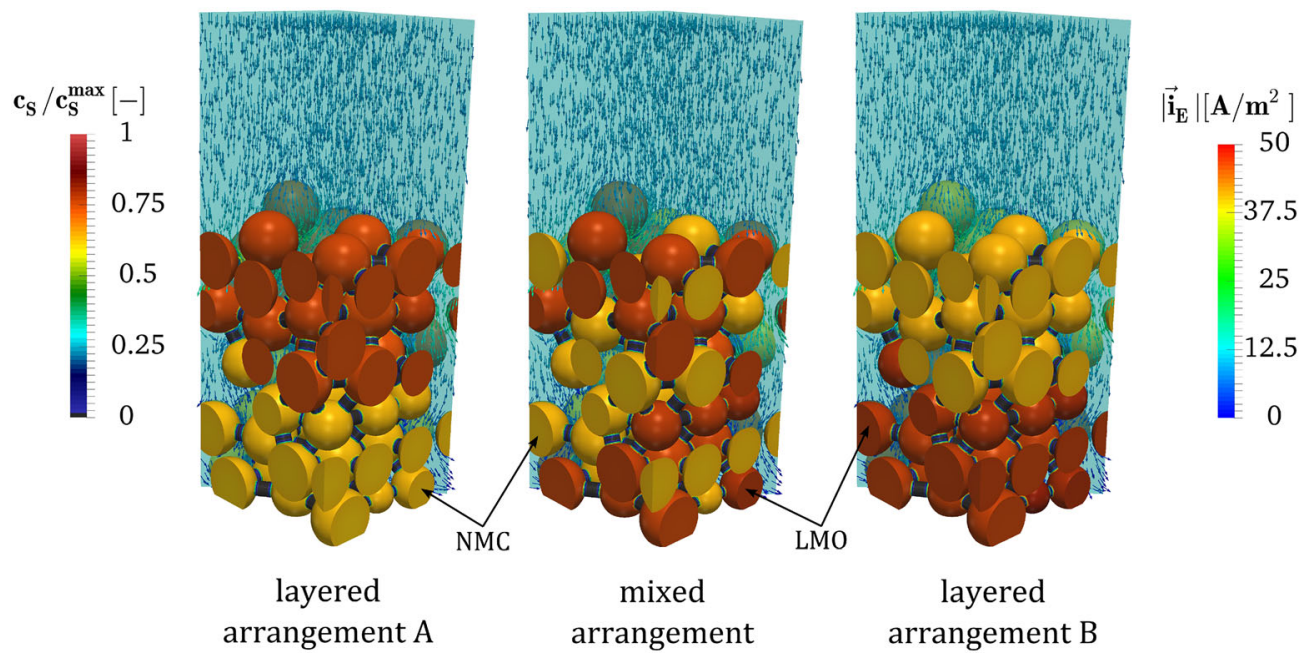

FIGURE 10 Three dimensional representation of the dimensionless lithium concentration $\frac{c_{S}}{c_{S}^{\text {max }}}$ and the ionic current density $\left|\overrightarrow{i_{E}}\right|$ within the electrode structures with varying particle arrangements. Herein, the result of a simulated galvanostatic discharge process at $0.5 \mathrm{C}$ and DOD 0.6 is shown [Colour figure can be viewed at wileyonlinelibrary.com]

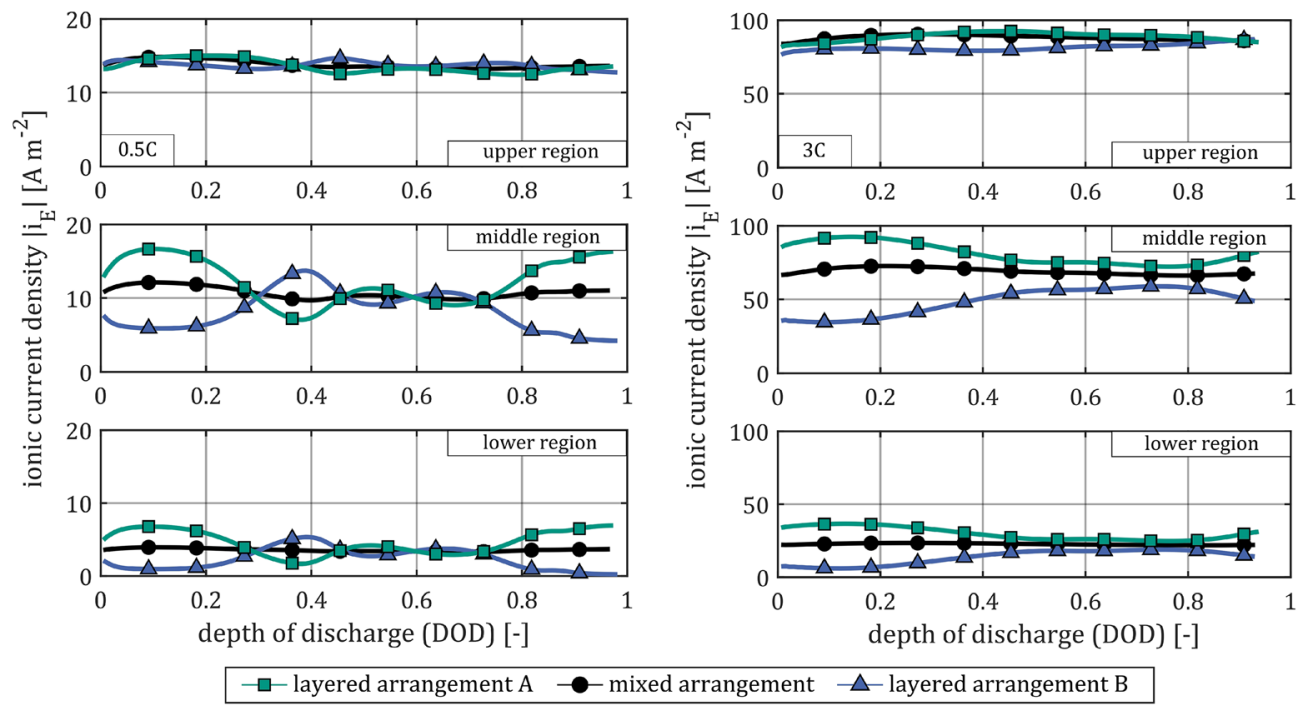

FIGURE 11 Layer wise evaluation of the ionic current density $\left|\vec{i}_{E}\right|$ within the electrolyte subdomain at a constant discharge rate of $0.5 \mathrm{C}$ (left) and 3C (right) [Colour figure can be viewed at wileyonlinelibrary.com]

within three horizontally arranged layers, each with identical layer thickness. While the region designated as the upper region includes the vicinity near the separator, the lower region is located close to the positive electrode's current collector. Accordingly, in the layered arrangements $\mathrm{A}$ and $\mathrm{B}$, the upper and lower regions include exclusively either NMC or LMO. The middle region represents the transition of both layers. In Figure 11, $\left|\overrightarrow{i_{E}}\right|$ represents the volumetrically averaged magnitude of the ionic current density for each layer.

For all considered electrode structures, a homogeneous current density distribution of comparable magnitude is present in the subdomain of the separator $\Omega_{E}^{S e p}$.
For this reason, this subdomain is not included in the stratified evaluation shown in Figure 11.

Figure 11 shows a decrease in the ionic current density towards the current collector because of the intercalation of lithium ions into the active material. Consequently, the magnitude of the ionic current density in the upper region of the considered electrodes exceeds the volumetric mean value of the entire electrode by about $50 \%$, regardless of the simulated discharge rate.

For both discharge rates shown, the ionic current density of the random particle arrangement shows a small temporal variation coefficient of $v_{t}<7 \%$. Because of the arbitrary arrangement of the active components and the spatially averaged evaluation, the influence of 
FIGURE 12 Layerwise evaluation of the relative nominal capacity related to the total nominal capacity of the investigated particle arrangements [Colour figure can be viewed at wileyonlinelibrary.com]

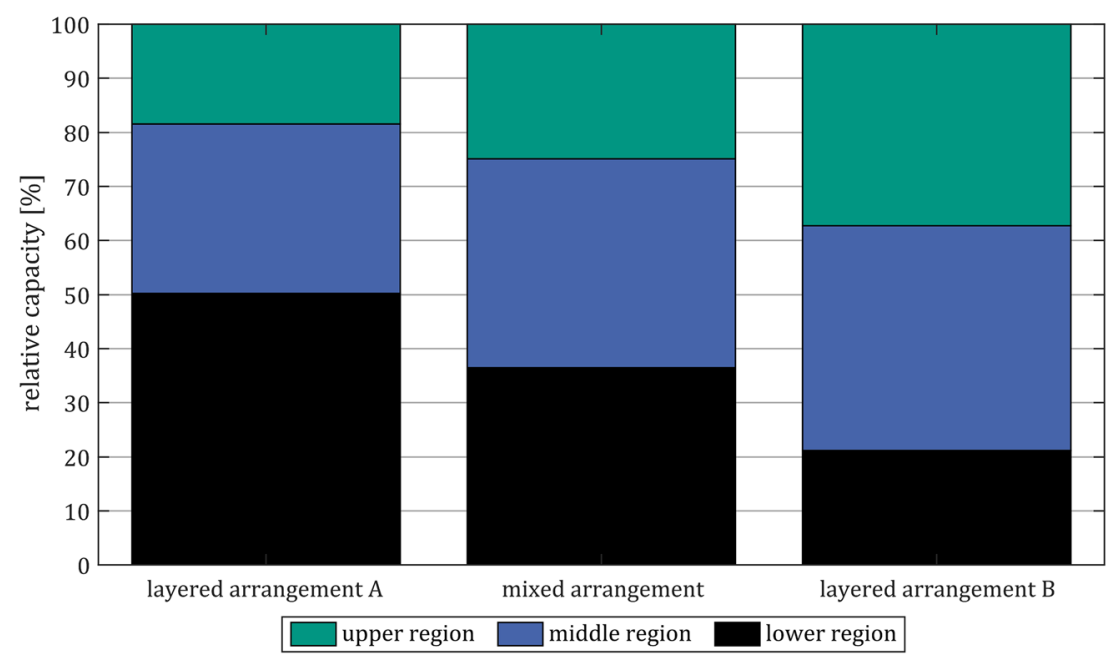

temporal variations in the intercalation behavior of both active materials on the local ionic current density is not observable.

For the stratified particle arrangements and especially at the low discharge rate of $0.5 \mathrm{C}$, it is recognizable that the temporal differences in the distribution of the intercalation current between the active materials have a direct influence on the magnitude of the ionic current density. As shown in the previous section, in the region of $0<D O D<0.2$, lithium uptake is dominated by the NMC component. Hence, the magnitude of the ionic current density of arrangement B is reduced by $61.9 \%$ and $94.3 \%$ compared with the reference electrode in the middle and lower section, respectively. When time averaged over the whole discharge cycle, the magnitude of the ionic current density of the entire electrode $\mathrm{B}$ is reduced by $4.5 \%$ with respect to the reference electrode.

Because of the increasing distance to the equilibrium state, an increase of the simulated discharge rates leads to a reduced temporal variation of the intercalation current between the two active components. As presented in the previous section, this manifests in a smoothened trend of the magnitude of the ionic current density $\left|\vec{i}_{E}\right|$ at a discharge rate of $3 \mathrm{C}$ (see Figure 11, right).

Furthermore, with increasing discharge rates, a dependency between the local composition in the form of the relative aeric capacity $K_{A}$ and the intercalation current within a layer is to be expected. This can be verified by means of a layerwise evaluation of the relative areic nominal capacity of the structures (see Figure 12).

Figure 12 compares the distribution of the relative nominal capacity of the considered electrode structures. Because of the higher stoichiometric maximum concentration of NMC compared with LMO, increased relative capacities can be seen in the vicinity of the NMC component. Hence, the relative capacity in the lower section of layered arrangement $\mathrm{A}$ is $37.7 \%$ higher compared with the reference electrode. In contrast, arrangement B exhibits a $49.8 \%$ higher relative capacity compared with the random particle arrangement in the separator-near region.

Because of the heating caused by high ionic current densities $^{24}$ and the associated temperature-induced degradation of the electrolyte, ${ }^{49,50}$ it is to be expected that the reduction of the magnitude of the ionic current density is beneficial for the cyclic aging behavior of a cell. Hence, with regard to the reduction of the average relative ionic current density within the porous electrode subdomain, the location of the largest relative capacities in the region close to the separator is beneficial. Correspondingly, in the middle and lower regions of arrangement $\mathrm{B}$, the temporal average magnitude of the ionic current density is $29.4 \%$ and $39.1 \%$ lower compared with the reference electrode. The time-average magnitude of the ionic current density within the entire porous structure of arrangement B is reduced by $11.2 \%$, compared with the reference electrode.

The transfer of the presented numerical results to real production processes of positive blended electrodes is realizable by means of multilayer coating processes. For this purpose, the active components are to be dispersed in separate coating slurries. These slurries are in the following to be fed to the coating unit according to the desired stratification. An example for this approach can be found in experimental studies of Liu et al, ${ }^{51}$ who used a simultaneous slot-die coating process to fabricate electrodes consisting of two layers containing different kinds of conductive additives, namely graphite and carbon black. 


\section{CONCLUSION}

In this contribution, the numerical simulation of blended electrodes consisting of different proportions of the active components $\mathrm{LiMn}_{2} \mathrm{O}_{4}$ (LMO) and $\mathrm{Li}\left[\mathrm{Ni}_{1 / 3} \mathrm{Co}_{1 / 3} \mathrm{Mn}_{1 / 3}\right] \mathrm{O}_{2}$ (NMC) is presented. On the macroscopic level, it turned out that, up to discharge rates less than $5 \mathrm{C}$, the utilizable capacity rises with an increasing proportion of LMO. Because of a smaller rate constant of the intercalation reaction $k_{B V}$ for LMO compared with NMC, this relationship was reversed at higher discharge rates.

On the particulate level, it could be shown that there are significant variations in the distribution of the intercalation current between the two material fractions during discharging. At the beginning and the end of a discharge cycle and regardless of the material composition of the blended electrode, most of the intercalation current was taken up by the NMC component. From this observation, an operating window of the blended electrode in the range of $0.2<D O D<0.8$ was identified. Furthermore, a reduction in the maximum lithium concentration difference within the NMC component could be determined in the presence of LMO. The relaxation of the maximum concentration difference was further positively influenced by an increasing proportion of LMO and a reduction of the discharge rate. Spatial gradients in the lithium concentration are related to mechanical stresses within the active material particles, which are known as one reason for its degradation. Consequently, a reduction of the maximum concentration gradients within the NMC component is an indication for an increasing cyclic aging resistance of a blended electrode consisting of LMO and NMC, when operated within the designated operating window.

In addition, it was shown that the layered arrangement of the active components within an electrode affects the magnitude of the ionic current density within the electrolyte during a discharge cycle. The numerical results revealed that, in comparison to the random particle arrangement, the separator-near arrangement of NMC allows a reduction of the ionic current density of up to $11.2 \%$. This was due to the higher volumetric capacity of NMC compared with the LMO component. Accordingly, a tailor-made layered arrangement of the active materials within blended electrodes appears to be highly attractive, especially for high-performance applications.

The stratification of electrodes is practically realizable by means of multilayer coating, ie, by using a simultaneous slot-die coating unit. Hence, these kinds of processes appear to be a valuable addition to known manufacturing processes, as they allow the production of optimized positive electrodes of lithium-ion batteries.

It is known that the active material surface area of an electrode influences the intercalation flux density, which affects the local overpotential and therefore macroscopically affects the half-cell potential. Hence, it is to be expected that the size, shape, and roughness of the active materials directly affects the half-cell performance. A simulation-based quantification of this effect is part of further investigations in this field.

Furthermore, the numerical model will be extended by the linear elasticity model. This enables the numerical simulation of mechanical stresses at small strains within the particulate structure of lithium-ion batteries, which helps to quantify the effect of mechanical degradation of the active material particles.

\section{ACKNOWLEDGEMENTS}

The authors like to express their thanks to Professor Ellen Ivers-Tiffée, André Weber, and Janina Costard for the excellent cooperation, the many fruitful discussions, and in particular, the provided experimental data. Furthermore, we gratefully acknowledge funding and support by the German Research Fooundation (Deutsche Forschungsgemeinschaft [DFG]) within the research training group SiMET under the project number 281041241/GRK2218. Moreover the authors acknowledge support by the state of Baden-Württemberg through bwHPC.

\section{NOMENCLATURE}

\section{Latin letters}

\begin{tabular}{lll} 
Symbol & Unit & Description \\
$c$ & {$\left[\mathrm{~mol} \mathrm{~m}^{-3}\right]$} & Concentration \\
$D$ & {$\left[\mathrm{~m}^{2} \mathrm{~s}^{-1}\right]$} & Diffusion coefficient \\
$F$ & {$\left[96485 \mathrm{C} \mathrm{mol}^{-1}\right]$} & Faraday number \\
$f_{ \pm}$ & {$[\mathrm{d}$} & Mean molar activity coefficient \\
$H$ & {$[\mathrm{~m}]$} & Cathode thickness \\
$\vec{i}$ & {$\left[\mathrm{~A} \mathrm{~m} \mathrm{~m}^{-2}\right]$} & Current density \\
\hline$K_{A}$ & {$\left[\mathrm{mAh} \mathrm{cm}^{-2}\right]$} & Areic nominal capacity \\
\hline$K_{g}$ & {$\left[\mathrm{mAh} \mathrm{g}^{-1}\right]$} & Gravimetric nominal capacity \\
\hline$k$ & {$\left[\mathrm{~m}^{2.5} \mathrm{~mol}^{-0.5} \mathrm{~s}^{-1}\right]$} & Material specific konstant \\
\hline$\vec{n}$ & {$[\mathrm{j}$} & Normal vector \\
\hline$\vec{n}$ & {$\left[\mathrm{~mol} \mathrm{~m}^{-2} \mathrm{~s}^{-1}\right]$} & Lithium flux density \\
\hline$R$ & {$\left[8.314 \mathrm{~J} \mathrm{~mol}^{-1} \mathrm{~K}^{-1}\right]$} & Universal gas constant \\
\hline$S_{V}$ & {$\left[\mu \mathrm{m}^{-1}\right]$} & Volume specific surface area \\
\hline$T$ & {$[\mathrm{~K}]$} & Temperature \\
$t$ & {$[\mathrm{~s}]$} & Time \\
\hline
\end{tabular}


(Continued)

\begin{tabular}{lll}
\hline Symbol & Unit & Description \\
$t_{+}^{0}$ & {[]} & Transfer coefficient \\
$U_{e q}$ & {$[V]$} & Open circuit potential \\
$x_{50}$ & {$[\mu \mathrm{m}]$} & Mean particle size \\
$z_{+}$ & {[]} & Charge number \\
\hline
\end{tabular}

\section{Greek letters}

\begin{tabular}{lll} 
Symbol & Unit & Description \\
$\alpha$ & {$[\mathrm{]}$} & Apparent transfer coefficients \\
$\Gamma$ & {$[\mathrm{]}$} & Boundary \\
$\Delta$ & {$[\mathrm{]}$} & Maximum difference \\
$\epsilon$ & {$[\mathrm{]}$} & Porosity \\
$\kappa$ & {$\left[\mathrm{S} \mathrm{m}^{-1}\right]$} & Conductivity \\
$\nu_{t}$ & {$[\mathrm{]}$} & Temporal variation coefficient \\
$\rho$ & {$\left[\mathrm{kg} \mathrm{m}^{-3}\right]$} & Density \\
$\tau$ & {$[\mathrm{]}$} & Tortuosity \\
$\Phi$ & {$[V]$} & Electrical potential \\
$\Psi$ & {$[\mathrm{C}]$} & Fraction of the intercalation current \\
$\Omega$ & {$[\mathrm{]}$} & Computational domain \\
\hline
\end{tabular}

\section{Subscripts/superscripts}

$\begin{array}{ll}0 & \text { Initial condition } \\ A & \text { Active material } \\ a & \text { Anodic } \\ B V & \text { Butler-Volmer } \\ c & \text { Cathodic } \\ D & \text { Diffusional conductivity } \\ E & \text { Electrolyte } \\ e q & \text { Equilibrium, ie, open circuit potential } \\ m & \text { Material }(m=L M O ; m=N M C \text { ) } \\ m a x & \text { Stoichiometric maximum concentration } \\ P & \text { Passive material fraction } \\ S & \text { Solid electrode } \\ \text { Sep } & \text { Separator }\end{array}$

\section{Abbreviations}

$D O D$ Depth of discharge

NCA Lithium-Nickel-Cobalt-Aluminum-Oxide $\left(\mathrm{LiNi}_{0.8} \mathrm{Co}_{0.15} \mathrm{Al}_{0.05} \mathrm{O}_{2}\right)$

LMO Lithium-Manganese-Spinel $\left(\mathrm{LiMn}_{2} \mathrm{O}_{4}\right)$
$N M C \quad$ Lithium-Nickel-Manganese-Cobalt-Oxide ( $\mathrm{Li}^{\mathrm{N}}\left[\mathrm{Ni}_{1 /}\right.$ $\left.{ }_{3} \mathrm{Co}_{1 / 3} \mathrm{Mn}_{1 / 3}\right] \mathrm{O}_{2}$ )

SEI Solid-electrolyte interphase

\section{REFERENCES}

1. Chikkannanavar SB, Bernardi DM, Liu L. A review of blended cathode materials for use in $\mathrm{Li}$ ion batteries. $J$ Power Sources. 2014;248:91 100 .

2. Heubner C, Liebmann T, Schneider M, Michaelis A. Recent insights into the electrochemical behavior of blended lithium insertion cathodes: a review. Electrochim Acta. 2018;269: 745760 .

3. Appiah WA, Park J, Van Khue L, et al. Comparative study on experiments and simulation of blended cathode active mate rials for lithium ion batteries. Electrochim Acta. 2015;187: 422432 .

4. Tran HY, Täubert C, Fleischhammer M, Axmann P, Küppers L, Wohlfahrt Mehrens M. $\mathrm{LiMn}_{2} \mathrm{O}_{4}$ spinel/ $\mathrm{LiNi}_{0.8} \mathrm{Co}_{0.15} \mathrm{Al}_{0.05} \mathrm{O}_{2}$ blends as cathode materials for Lithium ion batteries. $J$ Electrochem Soc. 2011;158(5):A556 A561.

5. Lu C H, Lin S W. Dissolution kinetics of spinel lithium manga nate and its relation to capacity fading in lithium ion batteries. $J$ Mater Res. 2002;17(6):1476 1481.

6. Kitao H, Fujihara T, Takeda K, Nakanishi N, Nohma T. High temperature storage performance of $\mathrm{Li}$ ion batteries using a mixture of $\mathrm{Li} \mathrm{Mn} \mathrm{spinel} \mathrm{and} \mathrm{Li} \mathrm{Ni} \mathrm{Co} \mathrm{Mn}$ oxide as a positive electrode material. Electrochem Solid St. 2005;8(2):A87.

7. Smith AJ, Smith SR, Byrne T, Burns JC, Dahn JR. Synergies in blended $\mathrm{LiMn}_{2} \mathrm{O}_{4}$ and $\mathrm{Li}\left[\mathrm{Ni}_{1 / 3} \mathrm{Mn}_{1 / 3} \mathrm{Co}_{1 / 3}\right] \mathrm{O}_{2}$ positive electrodes. $J$ Electrochem Soc. 2012;159(10):A1696 A1701.

8. Numata T, Amemiya C, Kumeuchi T, Shirakata M, Yonezawa M. Advantages of blending $\mathrm{LiNi}_{0.8} \mathrm{Co}_{0.2} \mathrm{O}_{2}$ into $\mathrm{Li}_{1+\mathrm{x}} \mathrm{Mn}_{2-\mathrm{x}} \mathrm{O}_{4}$ cathodes. J Power Sources. 2001;97 98:358 360.

9. Albertus P, Christensen J, Newman J. Experiments on and modeling of positive electrodes with multiple active mate rials for Lithium ion batteries. J Electrochem Soc. 2009;156(7): A606.

10. Doyle M, Fuller T, Newmann J. Modeling of galvanostatic charge and discharge of the lithium/polymer/insertion cell. $J$ Electrochem Soc. 1993;140(6):1526 1533.

11. Park J, Seo JH, Plett G, Lu W, Sastry AM. Numerical simula tion of the effect of the dissolution of $\mathrm{LiMn}_{2} \mathrm{O}_{4}$ particles on $\mathrm{Li}$ ion battery performance. Electrochem Solid St. 2011;14(2): A14 A18.

12. Ramadass P, Haran B, Gomadam PM, White R, Popov BN. Development of first principles capacity fade model for $\mathrm{Li}$ ion cells. J Electrochem Soc. 2004;151(2):A196 A203. 
13. Mao Z, Farkhondeh M, Pritzker M, Fowler M, Chen Z. Multi particle model for a commercial blended lithium ion electrode. Journal of The Electrochemical Society. 2016;163(3):458 469.

14. Lu T, Luo Y, Zhang Y, Luo W, Yan L, Xie J. Degradation analysis of a lithium ion battery with a blended electrode. J Electrochem Soc. 2017;164(2):A295 A303.

15. Jung S. Mathematical model of lithium ion batteries with blended electrode system. J Power Sources. 2014;264:184 194.

16. Mao Z, Farkhondeh M, Pritzker M, Fowler M, Chen Z, Safari M. Model based prediction of composition of an unknown blended Lithium ion battery cathode. J Electrochem Soc. 2015;162(4): A716 A721.

17. Newman J, Tiedemann W. Porous electrode theory with battery applications. AIChE J. 1975;21(1):25 41.

18. García RE, Chiang Y M, Carter WC, Limthongkul P, Bishop CM. Microstructural modeling and design of rechargeable lithium ion batteries. J Electrochem Soc. 2005;152(1):A255 A263.

19. Less GB, Seo JH, Han S, et al. Micro scale modeling of Li ion batteries: parameterization and validation. $J$ Electrochem Soc. 2012;159(6):A697 A704.

20. Wiedemann AH, Goldin GM, Barnett SA, Zhu H, Kee RJ. Effects of three dimensional cathode microstructure on the performance of lithium ion battery cathodes. Electrochim Acta. 2013;88:580 588 .

21. Kespe M, Nirschl H. Numerical simulation of lithium ion battery performance considering electrode microstructure. Int J Energy Res. 2015;39(15):2062 2074.

22. Kespe M, Hammerich S, Gleiß M, Nirschl H. Numerical optimi zation of the spatial conductivity distribution within cathode microstructures of lithium ion batteries considering the cell performance. Int. J. Energy Res. 2017;41(14):2282 2296.

23. Newman J, Thomas Alyea KE. Electrochemical systems. John Wiley \& Sons; 2012.

24. Latz A, Zausch J. Thermodynamic consistent transport theory of Li ion batteries. J Power Sources. 2011;196(6):3296 3302.

25. Doyle M, Newmann J, Gozdz A, Schmutz C, Tarascon J M. Comparison of modeling predictions with experimental data from plastic lithium ion cells. J Electrochem Soc. 1996;143(6): 18901903.

26. Thorat IV, Stephenson DE, Zacharias NA, Zaghib K, Harb JN, Wheeler DR. Quantifying tortuosity in porous Li ion battery materials. J Power Sources. 2009;188(2):592 600.

27. Hutzenlaub T, Thiele S, Paust N, Spotnitz R, Zengerle R, Walchshofer C. Three dimensional electrochemical Li ion bat tery modelling featuring a focused ion beam/scanning electron microscopy based three phase reconstruction of a $\mathrm{LiCoO}_{2}$ cath ode. Electrochim Acta. 2014;115:131 139.

28. Fang W, Kwon OJ, Wang CY. Electrochemical thermal modeling of automotive $\mathrm{Li}$ ion batteries and experimental val idation using a three electrode cell. Int J Energy Res. 2010;34(2): 107115.

29. Barker J, Pynenburg R, Koksbang R. Determination of thermo dynamic, kinetic and interfacial properties for the $\mathrm{Li} / \mathrm{Li}_{\mathrm{X}} \mathrm{Mn}_{2} \mathrm{O}_{4}$ system by electrochemical techniques. $J$ Power Sources. 1994;52(2):185 192.
30. Zhang X, Shyy W, Marie Sastry A. Numerical simulation of intercalation induced stress in Li ion battery electrode particles. J Electrochem Soc. 2007;154(10):A910 A916.

31. Christensen J, Newman J. A mathematical model of stress gen eration and fracture in lithium manganese oxide. $J$ Electrochem Soc. 2006;153(6):A1019 A1030.

32. de Vasconcelos LS, Xu R, Li J, Zhao K. Grid indentation analysis of mechanical properties of composite electrodes in Li ion batte ries. Extrem Mech Lett. 2016;9:495 502.

33. Costard J, Joos J, Weiss M, Ivers Tiffée E. Charge transfer parameters $\left(\mathrm{r}_{\mathrm{CT}}, \mathrm{j}_{0}\right.$ and $\left.\mathrm{k}\right)$ determined by combining tomography analysis with impedance modelling. Meeting Abstracts. 2016; 2:213.

34. Costard J, Ivers Tiffée E. “Combined impedance study (EIS) and microstructure analysis (FIB/SEM) of intercalation electrodes: determination of charge transfer parameters," in Book of Abstracts, 2017, p. 103.

35. Costard J. Einfluss von Mikrostruktur und Materialparametern auf die Leistungsfähigkeit poröser Elektroden für Lithium Ionen Batterien. KIT Scientific Publishing; 2018.

36. Djian D, Alloin F, Martinet S, Lignier H, Sanchez JY. Lithium ion batteries with high charge rate capacity: influence of the porous separator. J Power Sources. 2007;172(1):416 421.

37. Bauer W, Nötzel D, Wenzel V, Nirschl H. Influence of dry mixing and distribution of conductive additives in cathodes for lithium ion batteries. J Power Sources. 2015;288:359 367.

38. Zheng H, Tan L, Liu G, Song X, Battaglia VS. Calendering effects on the physical and electrochemical properties of $\mathrm{Li}\left[\mathrm{Ni}_{1 / 3} \mathrm{Mn}_{1 / 3} \mathrm{Co}_{1 / 3}\right] \mathrm{O}_{2}$ cathode. J Power Sources. 2012;208:52 57.

39. Zheng H, Liu G, Song X, Ridgway P, Xun S, Battaglia VS. Cath ode performance as a function of inactive material and void fractions. J Electrochem Soc. 2010;157(10):A1060 A1066.

40. Heubner C, Liebmann T, Lämmel C, Schneider M, Michaelis A. Internal dynamics of blended Li insertion electrodes. J Energy Storage. 2018;20:101 108.

41. Carslaw HS, Jaeger JC. Conduction of heat in solids. 2 Clarendon press Oxford; 1997.

42. Bohn E, Eckl T, Kamlah M, McMeeking R. A model for Lithium diffusion and stress generation in an intercalation storage parti cle with phase change. J Electrochem Soc. 2013;160(10): A1638 A1652.

43. Vetter J, Novák P, Wagner MR, et al. Ageing mechanisms in lithium ion batteries. J Power Sources. 2005;147(1 2):269 281.

44. Malavé V, Berger JR, Zhu H, Kee RJ. A computational model of the mechanical behavior within reconstructed $\mathrm{Li}_{\mathrm{x}} \mathrm{CoO}_{2}$ Li ion battery cathode particles. Electrochim Acta. 2014;130: 707717.

45. Kespe M, Keller F, Dörfler W, Nirschl H. Numerische untersuchungen interkalationsinduzierter spannungen in elektrodeneinzelpartikeln von lithium ionen batterien. Chemie Ing Tech. 2013;85(12):1878 1887.

46. Klinsmann RM. Markus and Rosato, Daniele and Kamlah, Marc and McMeeking, "modeling crack growth during Li extraction in storage particles using a fracture phase field approach,". $J$ Electrochem Soc. 2016;163(2):A102 A118. 
47. Klinsmann M, Rosato D, Kamlah M, McMeeking RM. Modeling crack growth during Li insertion in storage particles using a fracture phase field approach. J Mech Phys Solids. 2016; 92:313 344 .

48. Huttin M, Kamlah M. Phase field modeling of stress generation in electrode particles of lithium ion batteries. Appl Phys Lett. 2012;101(13):133902.

49. Botte GG, White RE, Zhang Z. Thermal stability of $\mathrm{LiPF}_{6} \mathrm{EC}$ : EMC electrolyte for lithium ion batteries. J Power Sources. 2001;97 98:570 575.

50. Abraham DP, Knuth JL, Dees DW, Bloom I, Christophersen JP. Performance degradation of high power lithium ion cells electrochemistry of harvested electrodes. J Power Sources. 2007; 170(2):465 475
51. Liu D, Chen LC, Liu TJ, Chu WB, Tiu C. Improvement of lithium ion battery performance by two layered slot die coating operation. Energy Technol. 2017;5(8):1235 1241. 


\section{Repository KITopen}

Dies ist ein Postprint/begutachtetes Manuskript.

Empfohlene Zitierung:

Kespe, M.; Cernak, S.; Gleiß, M.; Hammerich, S.; Nirschl, H.

Three-dimensional simulation of transport processes within blended electrodes on the particle scale.

2019. International journal of energy research, 43.

doi: $\underline{10.5445 / / R / 1000097078}$

Zitierung der Originalveröffentlichung:

Kespe, M.; Cernak, S.; Gleiß, M.; Hammerich, S.; Nirschl, H.

Three-dimensional simulation of transport processes within blended electrodes on the particle scale.

2019. International journal of energy research, 43 (13), 6762-6778.

doi:10.1002/er.4616 